\title{
A RE-ASSESSMENT OF HOUSE PRICE INDICES: EVIDENCE FROM THE SPANISH MARKET
}

\author{
Paloma TALTAVULL DE LA PAZ ${ }^{1, *}$, Stanley McGREAL ML $^{2,3}$ \\ ${ }^{1}$ Department of Applied Economy Analysis, International Economy Institute, University of Alicante, \\ Campus de San Vicente del Raspeig, 03080 Alicante, Spain \\ ${ }^{2}$ Built Environment Research Institute, School of the Built Environment, University of Ulster, UK \\ ${ }^{3}$ School of Commerce, Division of Business, University of South Australia, Australia
}

Received 11 September 2015; accepted 10 January 2018

\begin{abstract}
This paper using evidence from the Spanish housing market contributes significantly to the debate concerning the different results obtained from house price indices depending on the method used to build the index. Utilising a large database over the period 1994 to 2012, the paper constructs a time dummy hedonic index (HD) and an imputed hedonic index using a Laspeyres approach (HI), and compares the different effect on the price index evolution. The paper discusses control by quality changes and identifies those attributes experiencing structural changes over the analysis period, identified by the $\mathrm{HI}$ index but not by the HD index. Results indicate that changes in quality stem from socio-demographic conditions rather than changes to housing quality (other than size). The paper also shows that improvements in neighbourhood quality rather than change in a 'typical house' affects house price and argues that these considerations are important in both the method selected to calculate house price indices and the application of the methodology to estimate price changes.
\end{abstract}

Keywords: price index, housing market, hedonic models, Spain.

Supplementary material associated with this article can be found, in the online version, at https://doi.org/10.3846/ijspm.2019.6366

\section{Introduction}

In the post Global Financial Crisis era there has been increasing attention given to the construction of house price indices globally and particularly in European countries with a growing number of public institutions and governments publishing house price indices in an open-access format. This stems from the perception that house prices have macro-economic effects and that continuous monitoring in support of the identification of economic imbalances (European Economy [EU], 2012) facilitates transparency in the market. Given this context, a number of studies have focussed on the macro effects of house price deviation from their long term trend, the role of monetary channels of transmission influences, and the effect of the 'housing channel' on consumption prices (Mishkin, 2007; Bank for International Settlements [BIS], 2008; Taltavull \& White, 2016; R. Grover \& C. Grover, 2014), demonstrating the relevance of housing price indices. Furthermore, at the European level, the EU is advocating the building of price indices for member countries using the same methodology (Eurostat, 2013) and the requirement for central banks to capture market data (also for non-residential real estate markets ${ }^{1}$ ) in order to observe patterns in house prices. Furthermore, financial and investment institutions need reliable indices in updating their balance sheets in accordance with the mandatory regulations (Nikolov, 2014).

Most studies are based on the current price index published in each country but discussion has intensified concerning to what extent indices correctly reflect the true housing values. Consequently, the debate on house price index methodology has had a renewed interest in different forums. However, complexity arises from the heterogeneous nature of housing in terms of location, structure, composition and behaviour with price considered to represent how a household evaluates attributes according to income, education, quality and other characteristics. Such multiplicity of attributes makes it difficult to determine the best approach to the construction of house price indices. The consensus is that to capture the contribution of such

\footnotetext{
1 See the Greece Central Bank or the British Treasury as examples of different indices.
}

*Corresponding author. E-mail: paloma@ua.es 
factors, house prices need to be quality adjusted to reflect the interaction between characteristics, demand factors and perception of worth. Indeed, house prices may be influenced by the behaviour of consumers rather than an exact sum of their physical characteristics although such focus is rarely treated in house price index construction.

The hedonic model approach is viewed in many quarters as a robust technique capable of building house price indices taking regard of a range of factors. The Rosen (1974) definition refers to a 'joint-envelope function' which captures consumers' preferences with the hedonic equation embracing a combination of attributes and estimations possible from demand or supply side observations, dependent on model specification. Indeed, one of the merits of hedonic models is the ability to capture the weight of each attribute reflecting purchaser preference, willingness to pay or taste at a neighbourhood level (Tse, 2002). Hedonic models have become very popular in building house price indices controlled by quality (Herath \& Maier, 2010). However, index construction has often followed traditional methodology based on Laspeyres or Paasche indices (Coulson, 2012; Case \& Wachter, 2005; Goh, Costello, \& Schwann, 2012) with the impact of behavioural effects captured by allowing attributes to vary over time reflecting changes in tastes (see Hill, 2011 for a literature summary).

This paper focuses on dissimilarities in house price indices resulting from the use of various methodologies with the objective of testing for differences between indices calculated using two hedonic methods: one allowing the shadow price to vary over time (HI) and the other based on time dummies (HD) not allowing this variation both controlling by location. The results from these models are compared with one of the two official indices for Spain, the Ministery of Fomento index ${ }^{2}$. The indices in this paper are constructed using asking or list prices, thereby capturing the supply side of the market, while also being consistent with the methodology used by the official Spanish institution above. Significantly, in economic and policy terms, the findings from the indices constructed in this paper indicates that the main reason for price growth over a long period has been the increase in the quality of houses during the period of price expansion and the perception of Spanish house prices experiencing irrational growth is shown to be unfounded. The paper also suggests

\footnotetext{
2 There are two official indices: the INE (Spanish National Institute) index is based on transactions built from a hedonic model, controlling by a limited number of characteristics and location, quarterly from 2007. It is built using the Eurostat methodology based on a hedonic definition of prices and it includes a small number of characteristics plus location, based on transaction information released by the Notary Official Institution. MFOM is the Ministry of Public Works (Fomento). Housing Directorate is in charge of house price statistics based on valuation information which is used to build a weighted index based on asking price per $\mathrm{m}^{2}$. It is also quarterly based and available since 1987.
}

that the emphasis on using hedonics potentially ignores the role of general market fundamentals not captured by the changes in attribute prices.

The evidence underpinning this analysis is a micro database of properties with a large bundle of characteristics that include housing variables, accessibility to transport, building and neighbourhood amenities, and city features. The database covers urban areas of differing function and size. There is a particular focus on four provinces in Spain where sufficient observations are available to be both representative of the market and allow application of different index construction methodologies. Geographical coverage in the database includes most of the Mediterranean coast from Barcelona to Murcia, plus the Madrid province. Through utilisation of this large and in many respects unique database, the originality of this paper lies in the varying evidence, reflected in the house price indices, from different housing markets using similar methodology. Furthermore, to the best of our understanding, this paper represents the first analysis for Spanish housing prices adding to the novelty of the research.

The paper consists of six further sections. In section one, literature sources on hedonic house price modelling and index models are reviewed, while section two provides fuller details on the database and estimation process utilised in this research. Section three elaborates further on the variables used in the analysis. In section four, results from the hedonic models are interpreted, while section five is a discussion on index relationships. Last section draws conclusions from the research and emphasises how economic and potential policy interpretations may be different depending on the mode of index construction.

\section{Literature review}

The literature on hedonic models is rich in terms of the volume and quality of papers (for example Rosen, 1974; Linneman, 1980; Haurin, Hendershott, \& Kim, 1991; Peek \& Wilcox, 1991; Geltner, 1993; Adair, Berry, \& McGreal, 1996; Clapp, 2004; Herath \& Maier, 2010; Hill, 2011; Goh et al., 2012). The perceived strength of hedonic models is their ability to control for housing quality, however there are downsides namely the potential of producing biased estimation of the price index. This may occur when the functional form is not specified correctly (misspecification bias), when all relevant hedonic characteristics are not included (omitted variable bias), when not all relevant houses are observed or some are more likely to be recorded than others (sample selection bias ${ }^{3}$ ), or the parameters have changed over time $e^{4}$. These conditions can produce biased parameters, although as Case and Wachter (2005), Coulson (2012) and others consider hedonic price meth-

\footnotetext{
3 See Gatzla and Haurin (1998).

4 Hill (2011) adds reproducibility as a problem with hedonics and Shiller (2008) discusses the different indexes resulting from the application of different techniques or variables.
} 
ods are reasonably robust to minor violations of these conditions. To address such problems, the repeat sales (Case \& Shiller, 1987; Shiller, 2008; Nagaraja, Brown, \& Wachter, 2014) method has been advocated using different price information for same the property transactions at different points in time. This method has been extended through the Freddie Mac and OFHEO indices but suffers from a lack of control of various attributes over time and from a lack of sufficient observations (Rappaport, 2007; McMillen, 2008). Hybrid models combining attributes of both repeat-sales and hedonic price methods have also been used (see for example Quigley, 1995; Case \& Shiller, 1987 and Shiller, 1993) although the method imposes the constraint that estimated shadow prices are time invariant. Wood (2005) contends that combined methods are important as houses are heterogeneous making sale prices difficult to predict and that market price is not easy to observe. For these reasons house prices are characterised by different datasets and by varying interpretations at different periods. Hedonic models commonly assume a loglinear relationship between price and attributes (Malpezzi, 2002; Sirmans, MacDonald, Macpherson, \& Zietz, 2006) but there is considerable debate concerning the arbitrary functional form assumption. The source of identification problems is the linearization pattern normally applied in non-linear hedonics without using all the information in the model (Ekeland, Heckman, \& Nesheim, 2002, 2004).

Recent studies have focussed on mainly three areas. Firstly, the role of heterogeneity among households on housing prices at a community level (Yinger, 2015) and specificities of regional house price construction (Ericson, Song, Winstrand, \& Wilhelmsson, 2013). Secondly, the role of spatial heterogeneity and correlation when estimating prices corrected by characteristics and controlling index construction by the spatial effects (Nappi-Choulet \& Maury, 2009; Helbich, Brunauer, Vaz, \& Nijkamp, 2013; Taltavull de La Paz, López, \& Juárez, 2017; Hill \& Scholz, 2016). Thirdly, addressing time through continuous (Waltl, 2016) or chained indices (Syed \& de Hann, 2017).

\subsection{House price indices construction}

The consensus in the literature is that estimation of house price indices (Coulson, 2012; Case \& Wachter, 2005; Quigley, 1995; Case \& Shiller, 1987; A. Ramalho \& J. Ramalho, 2011; Mack \& Martínez-García, 2011) has to take account of housing heterogeneity and location. Encapsulated within this is the key question concerning how to control by quality given the different nature of the commodity (housing) and the quantity consumed. However, beyond this initial point of agreement there is an apparent lack of consensus on how an index should be constructed though three main methods to build house prices indices are frequently reported in the literature (Rapport, 2008; Coulson, 2012; Goh et al., 2012; P. Maguire, Miller, Moser, \& R. Maguire, 2016).

The first approach, index weighting, takes a simple average of observed house prices in one period, using either the mean or the median. The weighting is calculated using the number of observed transactions in a specific location and is considered to represent the observed house price and thus ignores the heterogeneity problem. While such indices are more simple in terms of construction, their underlying weakness is not controlling for attributes (Hill, 2011; Goh et al., 2012), an observation that has been stressed consistently across the literature. For example, Wu, Deng, and Liu (2014) argued that the simple average method fails to take account of housing quality adjustment, nevertheless these authors observed that in emerging housing markets such as China the initial price index was based on a weighted average method. Furthermore, such approaches have received applicability in mature markets, with the median value method used by the National Association of Realtors in the US (Bollerslev, Patton, \& Wang, 2016).

The second method is the hedonic with prices corrected by quality through identifying attribute contribution to price, or shadow prices, and isolating the pure impact on prices. This is the main advantage of the hedonic approach but a fundamental challenge, again observed across the literature, is the requirement for extensive data sets (Clapman, Englund, Quigley, \& Redfearn, 2006) given the infrequency of sale (Wood, 2005; Rappaport, 2007; Bollerslev et al., 2016). The functional form in a hedonic equation (Equation 1) is akin to regression, where $P$ is the $\log$ of transaction prices, $x_{i t}$ is the ' $i$ ' house attributes matrix, $\beta_{i 1}$ and $\beta_{0}$ are the parameters to be estimated.

$$
P_{t}=\beta_{0}+\Sigma \beta_{i 1} x_{i t}+\mu_{t} \text {. }
$$

The hedonic perspective is utilized to build price indices either using time dummies to estimate quality controlled house prices index (HD - Time-Dummy Hedonic Models) or imputed prices (HI - Hedonic Imputed models) (Hill \& Melser, 2008; Diewert, Heravi, \& Silver, 2009; Dorsey et al., 2010) where the prices are predicted based on the property attributes (in both cases).

The HD index is generated using time dummy variables to capture the time dimension, also including housing characteristics to control for quality. It takes the functional form shown in Equation 2.

$$
P_{t}=\beta_{0}+\Sigma \beta_{i 1} x_{i t}+\Sigma \beta_{2 t} D_{t}+\mu_{t},
$$

where: $\beta_{0}$ refers to differences in location affecting prices (following Coulson, 2012); $x_{i t}$ refers to ' $i$ ' housing attributes; $D_{t}$ is the time dummy components allowing the estimation of the price index through the $\beta_{2}$ parameters; $\beta_{2 t}$ gives the price index controlled by quality; $\beta_{\mathrm{i} 1}$ reflects the shadow price of each ' $i$ ' characteristic.

Although the time-dummy hedonic has been used extensively (for example Ericson et al., 2013), the HD method is limited, as the estimation of time dummies is related to a constant attributes matrix and does not allow shadow prices of characteristics to change over time (Hill \& Melser, 2008; Silver \& Heravi, 2007). As argued by Bianconi and Yoshino (2013) this may over or under estimate the value of the index. The estimation is undertaken for the whole period and the index is obtained through 
the estimated dummy parameters whereas the imputed method allows the estimated parameters to vary over time.

The advantages of the imputed method (HI) are flexibility in the treatment of regression parameters and the ability to reduce the impact of the omitted variable bias (Syed \& de Hann, 2017) and this approach has become an increasingly popular method of index construction. Estimated prices are explained by the hedonic model, illustrated in Equation 3.

$$
\hat{P}_{t}=\hat{\beta}_{0}+\sum_{i=1 . . n} \hat{\beta}_{i 1} x_{i t} .
$$

In building the index, imputed hedonic indices reconstruct the price based on the attributes and their shadow prices. This method allows for changes in quality compared with a constant quality reference-the 'typical house', the attributes of which are the mean of the observed attributes in each property over the period. The quality controlled house price is estimated, based on a combination of standard attributes forming the 'typical house', from which the attribute structure is fixed in the base period through a definition of a base-bundle of characteristics (Case \& Wachter, 2005; Diewert, 2010) and then applied to the rest of observations (Equation 4$)^{5}$. The index takes the Laspeyres/Paasche/Fisher form (Griliches, 1991) with the typical house price as the reference $\left(\mathrm{Pm}_{\mathrm{ji} 0}\right.$ hat in equation (4), Coulson, 2012 and Case \& Wachter, 2005)

$$
I h_{j i t}=\frac{\left(\hat{P} m_{j i t}\right)}{\left(\hat{P} m_{j i o}\right)} * 100 \text {. }
$$

where: 'Pm'_hat is the estimated median prices at each point in time ' $t$ ' of a house ' $i$ ' in the city/neighbourhood ' $j$ '.

The imputed method is calculated through disaggregation by geographic level, though Goh et al. (2012) report increasing model instability when the index is calculated at finer levels of geographical disaggregation. Nevertheless, Diewert et al. (2009) conclude that the hedonic imputation method is better than hedonic time dummies in allowing for changing prices of characteristics over time and providing greater flexibility but at the cost of using-up more degrees of freedom and leading to a less reproducible estimate of overall price change between periods. Furthermore, the hedonic imputation method, employing a traditional Laspeyres/Paasche/Fisher index methodology, and using a quality adjusted function or fixed base comparison has received common usage (Coulson, 2012; Prasad \& Richards, 2008; Case \& Wachter, 2005). Some authors, for example Syed and de Hann (2017) have discussed the potential of a chain-linked index to overcome the comparability problems of direct indices and reducing the spread associated with Paasche-Laspeyres indices but observe that chaining may "introduce a drift in price comparison causing the chained index to deviate from the direct index" (p. 588). The impu-

\footnotetext{
5 Hill (2011, p. 30) refers to the 'Characteristics method', as 'those where an 'average dwelling is defined and prices are imputed to this hypothetical house as a function of its characteristics using the shadow prices derived from the hedonic model'.
}

tation method has been widely employed in the price index literature and has been found to be the best with lower error measures (Goh et al., 2012).

A third method, repeat sales, is only utilisable for properties transacted twice or more to estimate the index. This method is quality-controlled (Quigley, 1995) through adjusting the increase in prices for any improvements in the house. Repeat sales form the basis of many current indices including the known as Case-Shiller index (Standard and Poor's/Case-Shiller (SPCS) Home Price). However, the repeat sales index has received particular criticism on a number of grounds. First, that only a small percentage of properties have matching sales leading to aggregation bias. Second, that the subset may not be representative of the entire housing stock leading to sample selection bias. Third, that houses which resale frequently tend to appreciate at higher rates. Fourth, that short holding periods may capture significant improvement to properties thereby violating assumptions on constant quality (Maguire et al., 2016; Bollerslev et al., 2016; Goh et al., 2012). Indeed, Goh et al. (2012) identified that of five different models/variations they assessed, the repeat sales model was the least preferred.

The need to control for heterogeneity is recognised in the literature with a number of sources of quality differences identified. First attributes change over time, hence the composition of sold properties varies, for instance there may be a greater concentration of luxury homes transactions or second-homes thereby affecting prices (McMillen, 2008). Second the valuation of attributes change over space, for example a third room in a house could be more highly valued in cities or view could have distinct value depending on the particular market. Third the attractiveness of areas also changes over time due to demand tastes or characteristics making 'betas' shift and changing either the shadow prices or weights of attributes in contributing to final house prices (defined by McMillen, 2008, p. 573, as 'change in the structural explanatory variables' $)^{6}$. Thus, with respect to Equation 1 an ideal index should let the two parameters, $\left(\beta_{i 0}\right.$ measuring differences on space and $\beta_{i t}$ measuring the shadow prices) and the distribution of $X_{i t}$ vary.

6 Bias arising from spatial and time autocorrelation within data (Case \& Wachter, 2005) and from mean reversion and diffusion of innovation over space (Hwang \& Quigley, 2010) present further issues in index construction. Bias in hedonic price indices stemming from auto-regression in model residuals is well supported in the literature (Goodman \& Thibodeau, 1995) and the case has been made by several authors to extend methodology beyond hedonic techniques and incorporate spatio-time autoregressive models (Stimson, 1985; Anselin, 1999; Dubin, Pace, \& Thibodeay, 1998; Pace, Kelley, Gilley, Otis, \& Sirmans, 2000). These models are considered to reduce the problems of bias resulting from local observed and unobserved property/neighbourhood attribute correlations through introducing spatial and time parameters and providing more robust estimation for house price indices. These models require observation to be geo-referenced. 
The main problem with such indices is that changes in quality, with changes in taste, technology and time bring about changes in commodity characteristics (Coulson, 2012) and the need to reconsider the 'typical bundle' in recalculating the index. When weights of commodities in household consumption change, the index based on the original weight structure does not reflect the reality of prices and the new estimated prices, based on the different weights, are not homogeneous with each change in attribute structure generating a break in the statistical series.

Essentially, the Laspeyres index measures the price in period $t$ related to the base period of a bundle of commodities $\left(x_{1, t=0}, \ldots x_{n, t=0}\right)$, where a constant combination of commodities in the bundle at both periods measure how much the same bundle would cost in period $t$ (and the subsequent periods). The expression (Coulson, 2012) is as stated in Equation 5:

$$
I^{L}=\frac{\sum_{n=1}^{N} p_{n, t} x_{n, 0}}{\sum_{n=1}^{N} p_{n, 0} x_{n, 0}}=\sum_{n=1}^{N}\left(p_{n, t} / p_{n, 0}\right) w_{n, 0},
$$

where: $w_{n, 0}$ is the share of the actual commodity ' $n$ ' in the base period being equal to $p_{n, 0} x_{n, 0} / \Sigma p_{n, 0} x_{n, 0}$ (Eurostat, 2011, p. 3 and pp. 18-19); $I^{L}$ is the Laspeyres price index.

Coulson (2012) also proposes the inclusion of the intercept of the (non-linear) hedonic model to capture the value of all the characteristics of the housing market that are constant across the units in that market, reflecting house price differentials by cities or regions. Indeed, Coulson suggests that the intercept term could serve as arbitrage condition of the differences in price of structural attributes across locations ${ }^{8}$. In this context Coulson forwarded Equation 6 where betas are the hedonic parameters representing shadow prices of attributes $\left(X_{i}\right), \beta_{0 j}$ is the intercept of the hedonic equation at every ' $j$ 's' location and $s_{j}^{2}$ is the half of the estimated variance of the error in the hedonic equation as a bias correction ${ }^{9}$.

$$
I_{j}=\frac{\exp \left(\beta_{0 j}+\sum_{i=1}^{k} \beta_{j i} x_{i}+0.5 s_{j}^{2}\right)}{\exp \left(\beta_{01}+\sum_{i=1}^{k} \beta_{j 1} x_{i}+0.5 s_{1}^{2}\right)} \forall i \in k .
$$

The following sections of the paper takes into consideration the issues raised in the literature and applies the time dummy hedonic method (HD model) and the imputed price hedonic model (HI model) in calculating house price indices for four Spanish provinces and comparing the results with official indices for Spain.

\footnotetext{
7 This expression has their original notation. Its ' $n$ ' is equivalent to the combination of the ' $i$ ' attributes.

8 The more popular functional form in modelling house prices with hedonic methodology is the semi-log specification suggesting non-linear relationship among price and attributes. Such issues need to be taken into account in index calculation, adjusting the index by a share of the error variance from the estimation.

9 See Hill (2011, p. 22) for further discussion about the inclusion of the half of error term variance in the imputed price calculation.
}

\section{Data}

This section of the paper discusses the database that underpins the modelling and analysis used to generate house price indices initially at the country-wide level for Spain and subsequently for four selected provinces using a quarterly time series from Q1 1995 to Q3 2012.

A major strength of the database stems from the richness of the information in terms of the number of observations, the quality of the information, its geographical reach, locational attributes ${ }^{10}$, and the combination of variables available for each property. In total, the number of observations over the study period is over 3.36 million for the whole Spain, these are properties that have been used as comparable evidence in the valuation process ${ }^{11}$. Each observation has details at an individual house level (12 characteristics) ${ }^{12}$, the neighbourhood level (12 characteristics), at a city level (7 characteristics), and transportation and accessibility factors (3 characteristics). Variable descriptors and summary statistics are provided in Table $S 1^{13}$. These are complemented by a time variable (quarter and year), urban dependence, province and asking prices ${ }^{14}$, capturing in total 31 different attributes for each property. The degree of disaggregation and the flexibility of the database have allowed the analysis to control for groups of attributes following the classification of Bowen, Mikelbank and Prestegaard (2001) and the three location dimension framework of Kiel and Zabel (2008). Furthermore, the database captures the socioeconomic characteristics of the city and the neighbourhood including income level as well as measures of population flow and density ${ }^{15}$ (Table S1).

Observations are at property level (microdata) with both the spatial and time dimensions. However, the database has some limitations, in particular the exact location

${ }^{10}$ The dataset represents characteristics in different cities and housing markets, the reach of the data allows the estimated hedonic models to avoid the traditional problems of identification resulting from lack of information about unobserved attributes.

${ }^{11}$ Data provided by Tabimed a major valuation company, which had a significant presence in the Spanish market until 2012. Only a few other studies have a similar number of observations to this paper. Dorsey, Hu, Myre, and Wang (2010) use 1.1 million transactions and a spatial autoregressive version of hedonic model.

${ }^{12}$ Note that the database does not include number of rooms, which is common in other studies. The reason is that this variable is highly correlated with size and including it bias the parameters. The same occurs with number of bathrooms. To have a kitchen or living room had zero variance in the database and were excluded in the analysis.

${ }^{13}$ The table can be found in the supplemental material.

${ }^{14}$ In Spain, the asking-list price of properties is used in the valuation process. See McGreal and Taltavull $(2012,2013)$.

${ }^{15}$ Income level, population flow and density are measured as the valuer's perception when visiting/inspecting the property not in actual monetary terms. 
of each property is not available ${ }^{16}$ and although information is at the municipality level, neither postal codes nor geo-references are available. Hence, the study does not permit the utilization of a methodology based on the calculation of geo-distances between each pair of houses to build the spatio-time matrix (W) as advocated in other studies (Getis \& Ord, 1992).

The level of spatial reference in the database is restricted to the information captured by the variable 'urban dependence' which classifies cities into four categories, namely capital city of provinces (four provinces, level 4); the main city of each county ${ }^{17}$ (level 3); independent cities which are defined as those characterized by having their own services (transportation, health, education, level 2); and fourthly, dependent cities reliant either fully or in part on services from other cities (level 1). This classification although nominal has an implied hierarchy of importance and these four levels of urban structure are taken as the location reference in this paper. The database contains the exact date when the observations were taken allowing the construction of indices on a quarterly basis thereby enabling comparison with the official indices.

The database also includes five population variables, one of these (total population) is a numeric variable and the other four (growth, development, density and evolution) and income level are categorical in nature and capture the perception of the valuer (rather than a precise numerical figure) in relation to where the subject property is located. ${ }^{18}$

Building the indices database is dependent on the existence of sufficient quarterly observations over the period 1995-2012. Geographically, the analysis is restricted to provinces on the Mediterranean coast of Spain (and Madrid) thereby having a commonality of location at a macro level and similarities in housing markets.

\section{Empirical analysis and modelling}

The analysis follows a three-stage process using a loglinear specification.

First, a simple hedonic index (HD, Log Linear Time Dummy Hedonic Regression Model with Quality Adjustment $)$ is generated based on Equation $2\left(P_{j t}=\beta_{j 0}+\Sigma \beta_{j i 1} x_{j i t}+\right.$ $\left.\Sigma \beta_{j 2 t} D_{j t}+\mu_{j t}\right) ; 19$ The index is represented by the $\beta_{j 2 t}$ parameters and an example of model output is found in Table S2 (supplementary material). The output from this

\footnotetext{
${ }^{16}$ Not supplied by the company due to data protection.

${ }^{17}$ Each province has several counties, the number of which varies between provinces.

${ }^{18}$ Note this is not a monetary-based measure but a 'quality' perception at the household level of income based on the property and external signals. Hence income is a quality attribute perceived at the point of valuation and is similar to the valuer's sentiment on quality of shopping areas or other neighbourhood characteristics.

${ }^{19}$ Note that every $\beta_{j i}$ remains constant while the values of $x_{j i}$ change among the house attributes.
}

step is the HD house price index based on the parameters estimated from Equation 2 and represented as Equation 7. The indices have been normalized at 1998 (average of four quarters) and the time dummy (D) is quarterly based.

$$
I_{H D j t}=\exp \left(\hat{\beta}_{j 2 t}\right) \text {. }
$$

The large size of the database allows estimation of indices at the lowest urban area dimension and then reconstructed such that the provincial (' $k$ ') index is calculated by multiplying every ' $j$ ' urban level index by their weights in the total province observations in the quarter and estimated using Equation 8.

$$
I h_{H D, k t}=\sum_{\forall t, j} \hat{I} h_{H D, k j t}{ }^{*} Q_{j t} / Q_{k t},
$$

where: $I h_{H D}$,kt is the HD index corresponding to province ' $k$ ' at quarter ' $t$ '; $I h_{h d}{ } k j t$ is the index corresponding to the urban level ' $j$ ' belonging to province ' $k$ ' at quarter ' $t$ '; $Q_{j t}$ is the quantity of properties observed at quarter ' $t$ ' located in urban level ' $j$ ' in province ' $k$ '.

Second, house price is estimated from the simple hedonic model by imputation method (HI, following Equation 1, $P_{j t}=\beta_{j 0}+\Sigma \beta_{j i 1} \mathrm{x}_{j i t}+\mu_{j t}$ ) and the imputed (predicted) prices are used to build a Laspeyres ${ }^{21}$ index following Equation 6. The specification of the latter in this paper, the so-called as L3 - double imputation method (Hill \& Melser, 2008; Hill, 2011), is applied as it is efficient enough to reduce the underlying and remaining omitted variable bias.

Equation 1 permits an estimator of the shadow prices of attributes and as this by time period, the method allows the estimation of quarterly price by urban area and province, as illustrated in Equation 9 (first step of the calculation sequence).

$$
\log \hat{P}_{j t}=\hat{\beta}_{0 j t}+\sum_{i=1 . . n} \hat{\beta}_{j i t} x_{j i t}+0.5 s_{j}^{2} .
$$

Estimation of the value of the index in every quarter ' $t$ ' is the output as in Equation 10.

$$
I_{H I, j t}=\frac{\exp \left(\hat{\beta}_{0 j t}+\sum_{i=1}^{k} \hat{\beta}_{j i t} x_{j i t}+0.5 s_{j}^{2}\right)}{\exp \left(\hat{\beta}_{0 j 1}+\sum_{i=1}^{k} \hat{\beta}_{j i 1} x_{j i 1}+0.5 s_{1}^{2}\right)} .
$$

In this case, $P_{j i}-\hat{P}_{j t}$ refers to the price responses other than those related to location ' $j$ ' and ' $i$ ' attributes thereby capturing demand-factor impulses from the market.

Once $I_{H I, j t}$ 's are calculated, the HI index at upper level (provinces) is estimated by weighting the $\mathrm{HI}$ index at the urban level by the number of observations in the database (as explained in Equation 8 for HD). The HD indices are represented in Figure 1 for the four provinces analysed

\footnotetext{
${ }^{20}$ For instance, for Alicante province, the index is: $I_{h_{-} \text {Alicante }, t}=\sum_{j=1 . .4}\left[I_{h_{-} \text {Alic_r }, t}{ }^{*} Q_{\text {Alic_r }, t} / Q_{\text {Alic }, t}\right]$ with $r=4$ (da, ic, cc and pc) urban areas and $Q$ the number of observations by area.

${ }^{21}$ Only the Laspeyres index is calculated here following the empirical evidence that the Laspeyres type hedonic imputation index can provide a very close approximation to the theoretically ideal Fisher hedonic imputation index (Diewert, 2010, p. 24).
} 
and Figure 2 shows both the HD, HI and the official Spanish housing price index ${ }^{22}$. It is recognised that the level of aggregation causes some degree of constraint in the estimated index due to the absence of a specific space location variable. The total number of models estimated to build $\mathrm{HI}$ is $1136\left(71^{\star} 4^{\star} 4\right)$, after the derivation of each model, the estimated price value $\left(\hat{P}_{j t}\right)$, the estimation errors, variance of errors as well as the estimated parameters for the attributes $\left(\hat{\beta}_{j t}\right)$ are computed thereby allowing observation as to whether the impact on prices of the housing characteristics is monotonic over time.

In addition, as the bundle of attributes is heterogeneous, the analysis in this paper tests whether the attributes as such change in order to identify changes in quality and the effect on house prices. It is hypothesized that a change in quality is shown through a shift in characteristics and is captured as a structural change. The latter is tested using Zivot-Andrews Test for breaking points. The rationale for this successive exercise is firstly to test whether house price dynamics depend on the varying methodology underpinning index construction and secondly to examine the relevance of house price index definition.

\section{Results and discussions}

Initial comparison of the official indices for Spain shows that the MFOM index (not adjusted by quality) and the INE index (hedonic) coincide until 2011 and diverge afterwards (Figure S1). The house price data used in this paper follow a similar pattern which suggesting that the TABIMED database is representative of the Spanish market. Thus, the indices estimated in this paper essentially adhere to the same cycle as the official government indices (INE unit indices). However, different dynamics by urban area (four urban levels by four provinces) are apparent. Depending on the province, the drivers for house price growth are drawn from different tiers in the urban hierarchy (Figure 1) with the largest house price growth rate achieved by autonomous towns and province capitals though in the case of Valencia and Murcia higher growth rates are apparent in dependent urban areas. Between 2007 and 2011, most growth rates are negative showing the extent of house price correction, though some urban areas continued to experience positive growth rates during the crisis. For example, in Murcia this was observed for certain 'level 3' cities; and in Madrid and Alicante for 'level 4' cities.

\footnotetext{
${ }^{22} \mathrm{HI}$ calculations implicitly assume that a homogeneous 'typical' house exists in every period, that is, the typical house is allowed to change over time. In this paper, we test the extent of homogeneity over time (Table S3) in order to support the assumption of less bias from change in quality in HI index. The evidence that structural changes in relation to the 'typical house' are linked to accessibility or neighbourhood quality, supports the robustness of the $\mathrm{HI}$ index.
}

Alicante

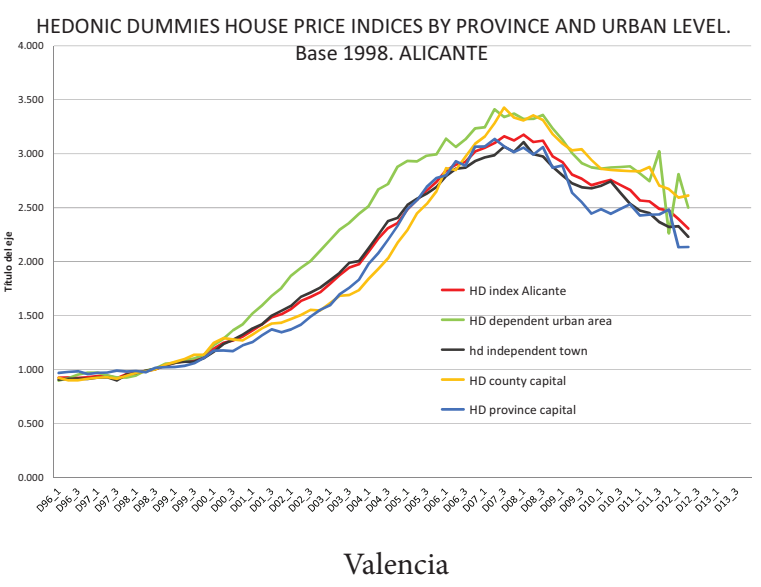

HEDONIC DUMMIES HOUSE PRICE INDICES BY PROVINCE AND URBAN LEVEL.

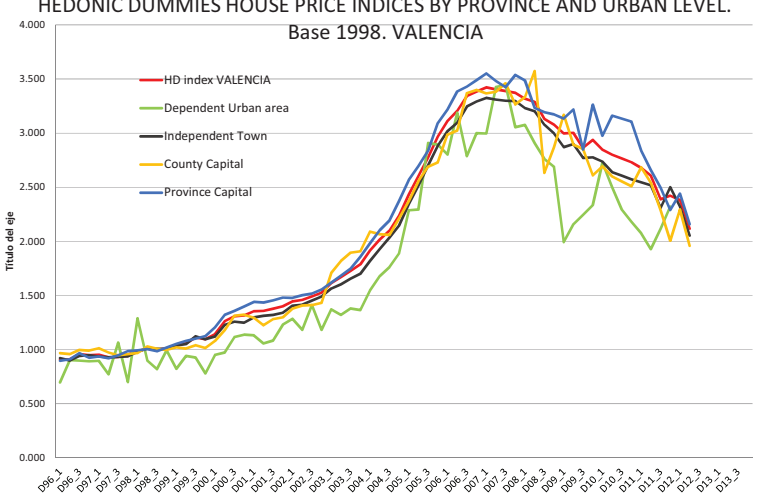

Madrid

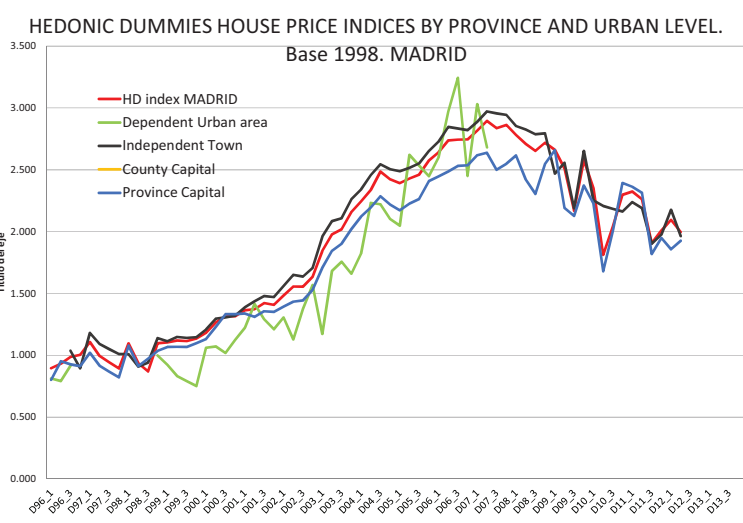

Murcia

HEDONIC DUMMIES HOUSE PRICE INDICES BY PROVINCE AND URBAN LEVEL.

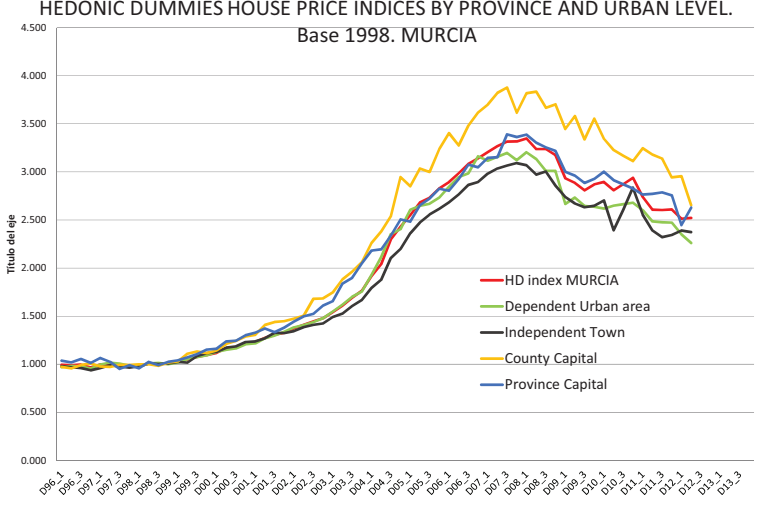

Figure 1. HD Indices at urban level. Seven Spanish provinces 
Alicante

ALICANTE. HD AND HI HEDONIC INDICES.* Base 1998=100

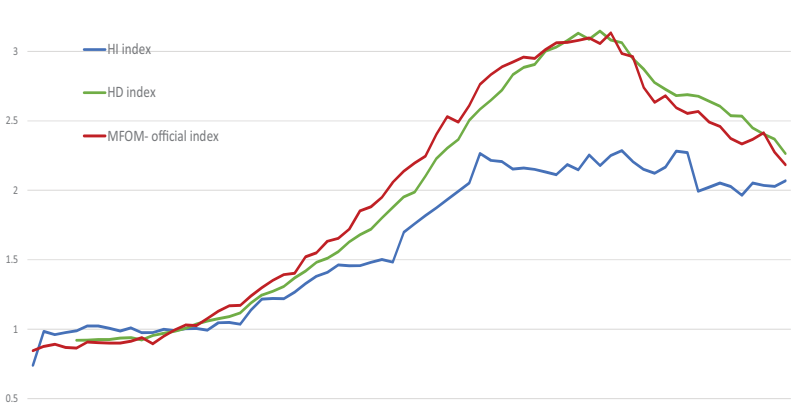

* Existing house prices. In MFoM is house prices for houses older than 2 years

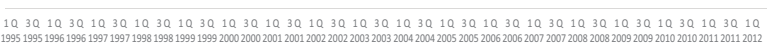

Valencia

VALENCIA. HD AND HI HEDONIC PRICE INDICES* Base 1998=100

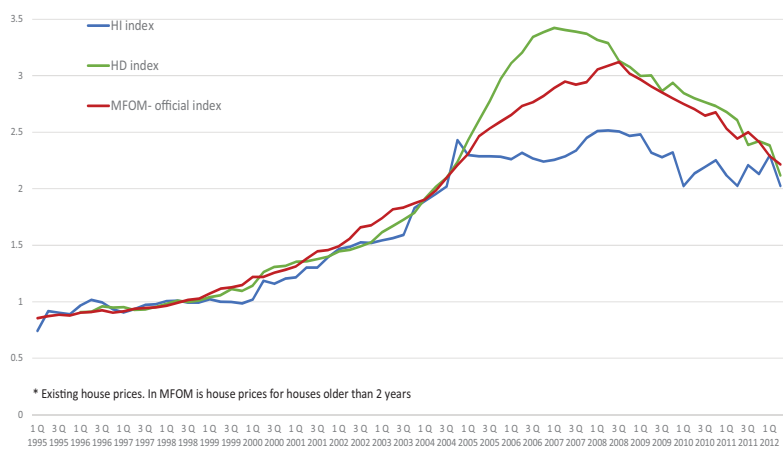

Madrid

MADRID. HD AND HI HEDONIC PRICE INDICES Base 1998=100
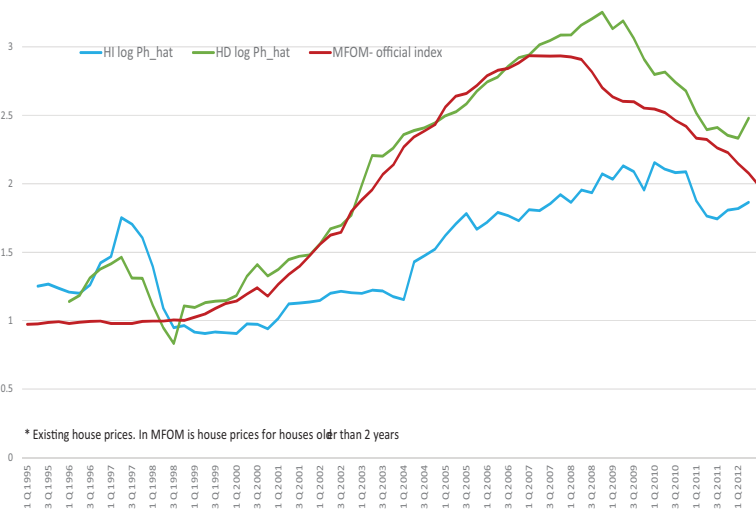

Murcia

MURCIA. HD AND HI HEDONIC INDICES*

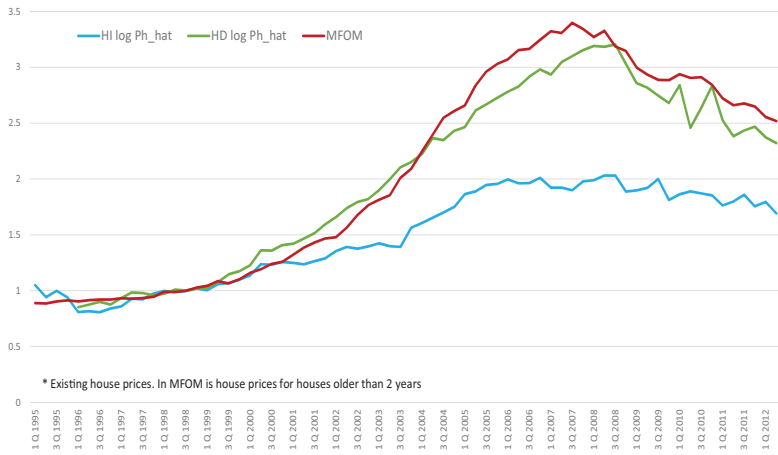

Figure 2. Hedonic indices and official house price comparison

\section{1. $\mathrm{HD}$ and $\mathrm{HI}$ hedonic indices}

Hedonics HD and $\mathrm{HI}$ are represented in Figure 2 at province aggregate level. The hedonic (HD) model infers that correcting by quality has several effects on the price estimated index, showing different patterns by province. In some provinces, the hedonic calculation reduces house price volatility (Alicante and Madrid provinces), while for the other provinces the hedonic correction shows greater volatility in house prices (Murcia and Valencia for some periods). These differences suggest that quality changes and conditions do not always modify the index in the same direction.

Differences in growth rate are substantial (Table 1) with the HI - Laspeyres index showing lower and less volatile house price growth rate than the HD index in all regions. During the period $1998-2012^{23}$, house price growth was in the range $25-45 \%$. The analysis highlights strong regional differences between the $\mathrm{HI}$ and the $\mathrm{HD}$

\footnotetext{
${ }^{23}$ Calculated since 1998 in order to have proper comparison for all provinces, as some provinces lack enough observations to estimate the index for the years 1995-1997 using a quarterly base.
}

indices during the expansion period (2004-2005) with convergence of the two indices in Murcia, but HI shows higher growth rates in Madrid. The recession period is characterised by negative house price growth rates in Valencia, Murcia and Alicante, whereas the Madrid still exhibited positive growth in house prices.

The role of each attribute is shown in Table 2 which details the estimated parameters explaining $\mathrm{HI}$ housing prices for Alicante province.

Those with larger marginal impact are (not surprisingly), size $\left(\beta_{m 2}=0.811\right)^{24}$ and type of building $\left(\beta_{\text {type }}=\right.$ 0.101 ), followed by a bundle of neighbourhood characteristics: quality of shops in the neighbourhood $\left(\beta_{\text {qshops }}=\right.$ 0.118 ), population density $\left(\beta_{p}=0.035\right)$, income (both in the neighbourhood and in the city, $\left(\beta_{\text {income }}=0.096\right.$ and 0.054 respectively), quality of leisure amenities ( $\beta_{\text {qleisure }}=$ 0.080 ), Resarea (residence typology in terms of first or secondary home, $\beta_{\text {resarea }}=0.092$ ), and economic activity in the area $\left(\beta_{\text {eco }}=0.035\right)$. Those attributes that are strictly

\footnotetext{
${ }^{24}$ Non standardized parameters are included into brackets although the order of relevance followed the standardized parameters in Table 2.
} 
Table 1. Urban area house prices growth rate in different periods (accumulate \%)

\begin{tabular}{|c|c|c|c|c|c|c|c|}
\hline \multirow{2}{*}{ Base 1998} & \multicolumn{4}{|c|}{ Urban level (Imputed hedonic - HI) } & \multirow{2}{*}{$\begin{array}{l}\text { 'Imputed- } \\
\text { hedonic (HI)' } \\
\text { (a) }\end{array}$} & \multirow{2}{*}{$\begin{array}{c}\text { 'Dummy } \\
\text { hedonic (HD)' } \\
\text { (b) }\end{array}$} & \multirow{2}{*}{$\begin{array}{c}\text { Differences } \\
(\%) \\
{[(\mathrm{a} / \mathrm{b})-1] \cdot 100}\end{array}$} \\
\hline & 1 & 2 & 3 & 4 & & & \\
\hline \multicolumn{8}{|c|}{ Alicante } \\
\hline $1998-2012$ & 89.5 & 117.7 & 84.8 & 114.3 & 108.6 & 146.1 & -25.7 \\
\hline 1998-2004 & 93.3 & 95.4 & 88.3 & 75.3 & 88.9 & 167.8 & -47.0 \\
\hline 2004-2007 & 38.5 & 16.5 & 21.5 & 1.2 & 16.2 & 29.9 & -45.8 \\
\hline $2007-2012$ & -20.3 & -6.0 & -16.1 & 20.8 & -5.3 & -28.6 & -81.4 \\
\hline \multicolumn{8}{|c|}{ Madrid } \\
\hline $1998-2012$ & & 54.0 & & 157.5 & 96.9 & 179.7 & -46.1 \\
\hline 1998-2004 & -2.1 & 30.6 & 16.1 & 39.4 & 31.1 & 152.2 & -79.6 \\
\hline $2004-2007$ & -39.2 & 55.8 & 24.3 & 66.8 & 56.9 & 25.7 & 121.4 \\
\hline $2007-2012$ & & -8.3 & -8.5 & 50.7 & 19.0 & -12.2 & -255.7 \\
\hline \multicolumn{8}{|c|}{ Murcia } \\
\hline $1998-2012$ & 79.7 & 69.5 & 34.4 & 83.1 & 70.9 & 130.0 & -45.4 \\
\hline 1998-2004 & 80.4 & 67.7 & 18.0 & 58.5 & 67.2 & 134.6 & -50.1 \\
\hline 2004-2007 & 26.2 & 15.5 & 21.7 & 26.3 & 19.7 & 32.0 & -38.6 \\
\hline $2007-2012$ & -18.9 & -11.9 & 8.2 & -11.9 & -12.1 & -23.8 & -49.4 \\
\hline \multicolumn{8}{|c|}{ Valencia } \\
\hline $1998-2012$ & 118.1 & 111.0 & 22.5 & 109.0 & 100.4 & 103.5 & -3.1 \\
\hline $1998-2004$ & 101.4 & 104.6 & 37.0 & 89.4 & 93.4 & 130.3 & -28.3 \\
\hline 2004-2007 & 15.2 & 21.3 & 22.1 & 18.1 & 19.2 & 47.1 & -59.3 \\
\hline $2007-2012$ & -11.8 & -12.2 & -26.3 & -9.4 & -11.5 & -38.6 & -70.3 \\
\hline
\end{tabular}

Table 2. Hedonic HI model for Alicante province

\begin{tabular}{|c|c|c|c|c|c|}
\hline \multicolumn{6}{|c|}{ Alicante } \\
\hline \multicolumn{2}{|c|}{ var dep: Log of asking prices } & $\beta$ & Standardized $\beta$ & Stand. error & \\
\hline & constant & 6.47 & - & 0.017 & $x * x$ \\
\hline \multirow[t]{6}{*}{ City (7) } & $\mathrm{PD}$ & 0.044 & 0.041 & 0.001 & $* * *$ \\
\hline & Pdev & -0.004 & -0.006 & 0.001 & $x * x$ \\
\hline & PGR & 0.039 & 0.026 & 0.001 & $* * *$ \\
\hline & $\mathrm{P}(\log s)$ & 0.035 & 0.115 & 0.000 & $x * *$ \\
\hline & Eco & 0.035 & 0.057 & 0.000 & $x * *$ \\
\hline & UENV & 0.158 & 0.025 & 0.004 & $* * *$ \\
\hline \multirow[t]{12}{*}{ Neighborhood (12) } & Inc & 0.054 & 0.057 & 0.001 & $* * *$ \\
\hline & Resarea & 0.092 & 0.072 & 0.001 & $* * *$ \\
\hline & Con & 0.001 & 0.017 & 0.000 & $* * *$ \\
\hline & URR & -0.001 & -0.030 & 0.000 & $* * *$ \\
\hline & Qroad & 0.020 & 0.005 & 0.003 & $* * *$ \\
\hline & Qw-pipe & -0.634 & -0.562 & 0.001 & $* * *$ \\
\hline & Qlig & -0.009 & -0.003 & 0.002 & $* * *$ \\
\hline & Qsh & 0.006 & 0.008 & 0.001 & $* * *$ \\
\hline & Qschool & 0.012 & 0.011 & 0.002 & $* * *$ \\
\hline & Qchurch & 0.049 & 0.044 & 0.002 & $* * *$ \\
\hline & Qleis & 0.080 & 0.088 & 0.001 & $* * *$ \\
\hline & Qhealth & -0.113 & -0.115 & 0.001 & $x * *$ \\
\hline \multirow[t]{3}{*}{ Accessibility (3) } & Bus & 0.007 & 0.011 & 0.000 & $\star * * *$ \\
\hline & Train & -0.002 & -0.002 & 0.001 & $* * *$ \\
\hline & Und-Tram & 0.029 & 0.069 & 0.000 & $* * * x$ \\
\hline \multirow{16}{*}{ House (12) } & TB & 0.101 & 0.098 & 0.001 & $* x *$ \\
\hline & dwel & -0.001 & -0.027 & 0.000 & $* * *$ \\
\hline & lift & 0.058 & 0.075 & 0.001 & $* * *$ \\
\hline & age & -0.008 & -0.194 & 0.000 & $* * *$ \\
\hline & Qshop_n & 0.118 & 0.211 & 0.000 & $* * *$ \\
\hline & Inc_t & 0.096 & 0.098 & 0.001 & $* * *$ \\
\hline & PD_t & -0.020 & -0.018 & 0.001 & $* * *$ \\
\hline & Ori & 0.003 & 0.013 & 0.000 & $* * *$ \\
\hline & $\mathrm{Vi}$ & 0.019 & 0.021 & 0.001 & $* * *$ \\
\hline & ConQ & 0.033 & 0.055 & 0.001 & $* * *$ \\
\hline & $\mathrm{m} 2(\log )$ & 0.811 & 0.400 & 0.001 & $x * *$ \\
\hline & m2_O (log) & 0.034 & 0.055 & 0.000 & $* * *$ \\
\hline & Adj $\mathrm{R}^{2}$ & 0.768 & & & \\
\hline & $\sum \mathrm{e} 2$ & 4357.188 & & & \\
\hline & $\mathrm{F}$ & $58081.547^{\star * *}$ & & & \\
\hline & $\mathrm{N}$ & 596170 & & & \\
\hline
\end{tabular}

Note: This Table 2 contains the average value of four urban level betas estimated for Alicante in 2010 (4 quarters). Total number of usable observations for Alicante (for the whole period) are 478418, and 11390 on average for every quarter of 2010. 
housing characteristics have smaller coefficients and in essence a lower ranking concerning the effect on prices (quality of construction, $\beta_{\text {urb_env }}=0.158$, orientation, $\beta_{o-}$ rient $=0.003$, view, $\beta_{\text {view }}=0.019$, additional surface area $\beta_{m 2 \_o t h e r}=0.034$, number of lifts $\beta_{\text {lift }}=0.058$, and quality of construction $\beta_{\text {qconstr }}=0.033$ ). This suggests that the main determinant for house prices are neighbourhood attributes. Hence, indices failing to control by location/ characteristics of the surrounding area could be biased. The effects of missing neighbourhood quality change thus limit the ability of the index to control by quality.

\section{Discussion}

As the HD estimations do not allow the attribute parameters to vary with time, the results suggest that the model structure reflects the weights given to each attribute during the first part of the time series period but differ from the pattern in the second period. The test for breaking points in attributes ${ }^{25}$ supports this argument and suggests that a change in quality accounts for part of the observed house price growth and that remaining differences reflect other price impulses. HI seems better placed at capturing the changes in quality while the HD model reflects exogenous influences ${ }^{26}$ such as the market influx on house prices from the demand side. One of these components could also be due to autocorrelation (spatial and time) in the data ${ }^{27}$.

Models from the HI Hedonic Imputed suggest that there is a pattern of initial growth characterised by rising house prices until 2005 followed by stable house prices suggesting that the share of price explained by property quality was increasing until 2005 but then stabilized. These results contrast with those from the HD model, notably over the period 2005-2010, illustrating that differences in house price growth and the extent of the level of growth is dependent on the methodology used. One interpretation ${ }^{28}$ is that the hedonic dummy method does not take into account variability in the price of attributes (assumed to be constant over the period by the method) hence the index loses its capacity to capture quality changes over time. By contrast $\mathrm{HI}$ allows the estimated betas to vary. It seems that the type of dwellings sold over the boom and bust periods

\footnotetext{
${ }^{25}$ Performed in the typical house's section 5.1.

${ }^{26}$ When the $P h \_h a t$ is estimate in a 'HD model, the values are equal to the observed asking prices. This is why it is not necessary to calculate an index using the traditional method (Laspeyres or Paasche), in a model controlled by attributes plus time dummies. The time dummies capture any external influence on prices.

${ }^{27}$ Note that papers explaining imputed price methods based on traditional indices (Laspeyres, Paasche or Fisher) using the estimated prices obtained directly from a hedonic model do not allow intercept and attribute parameters to change over time and then capture the time effect.

${ }^{28}$ We want to thanks to an anonymous referee for provide this highlight.
}

have varied to the point that either the relative prices of attributes changed or that comparing the reference house at the end of the period to the same house at the beginning does not make sense. Such reaction could be capturing changes in the type of house sold over time and may also reflect changes in market liquidity. For example, during the boom practically any type of unit was easily sold, even if of low quality, hence the rising quality adjusted prices while during the bust, the number of transactions declined and only certain types of dwellings were sold. One would have expected that only the very good houses got sold, so that the quality increase was such that the price would decline even more when adjusting for quality.

The house price index evolution compared in Figure 2 suggests that $\mathrm{HD}$ and $\mathrm{HI}$ are measuring different concepts. The HI construction estimated price of the total attributes, letting the errors capture the increase in price due to other factors (as defined by Rosen). In essence, the HI models essentially provide an index of quality rather than an index controlled by quality, whereas the HD models isolate house prices from their components (time and attributes) obtaining an index adjusted by quality. The different methods of construction mean that the interpretation of $\mathrm{HI}$ indices is not the same as that for HD indices; the former are indices of quality prices and the latter indices of house price controlled by quality. Thus both are complementary rather than substitutive, and both partially capture true quality controlled house price. As a consequence, in the case of $\mathrm{HI}$ the price growth rate could be calculated based on the equation residuals rather than on the imputed prices whereas in the case of a HD index, the equation to estimate dummy parameters includes a sufficient number of characteristics to control by quality though the effect on prices of the unobserved or omitted key attributes may produce an index not fully controlled by quality.

\subsection{The 'typical house'}

A further point of discussion relates to estimation of the 'typical house' attributes structure to guarantee that the index is controlling by changes in quality and the assumption that it can change over time, explaining the results found in the two estimated indices. In this respect, some evidence about changes in quality of the whole stock is needed to identify whether this type of change occurs and when. In the case of no statistically significant changes in housing attributes (which determines the 'type of house' in the long term), a house price index measuring the same initial attribute structure should be precise in capturing price changes. However, a change in attributes could introduce a bias in the estimated house price index capturing 'inexistent shifts' in prices and in fact actually measuring changes in the type of house on the market. To illustrate this point further, the current database is used to identify shifts in quality (attributes) over the time. Table S3 (supplementary material) shows the significance of Zivot-Andrews test of breaking points and its application to the density distribution for categorical variables and ex- 
treme percentiles $(5 \%, 25 \%$ and $75 \%, 95 \%$ and $99 \%$ of the distribution) for continuous variables. It is expected that a break point being statistically significant gives information about the changes in quality as well as the time when it occurs. Specifically, the results add evidence about the change in Alicante province and, indirectly, the accuracy of the estimated indices.

The Zivot-Andrews test confirms that many of the attributes experience a structural change in their median around 2005-2006 mostly in certain categories. Those variables experiencing structural change in all categories are income at city and at neighbourhood level, train and underground proximity, and size of the property $\left(\mathrm{m}^{2}\right)$. The latter suggests a dramatic change in house size since 2004-2005 while the former captures change in income affecting housing prices in 2005. Other parameters show a change in the upper attribute categories. For example, population (development, density and growth) shows breaks in 2005 in their higher categories (high density, growth stable and positive, and population breaking the median in the right tail of distribution namely the more populated cities). Spatially breaks are apparent in locations with primary homes associated with good or very good road quality, with expansion of the shop network (in areas with bad and poor quality), improvements in accessibility by train and underground, in apartment buildings, and with low density. At a property level, the Zivot-Andrews test finds that lower density buildings report a break in the median for both poor views (common in apartment buildings) and very good views (with the best locations). The test also reports a change in construction quality also during 2005.

The results suggest that most changes in housing attributes have taken place during 2004-2005 and many of them across the neighbourhood characteristics. This supports the contention that the 'typical house' has remained mostly unchanged (changing mainly the size) and other attributes are significant only for a particular quartile of the distributions confirming that the main sources of price change comes from location and improvements in facilities and amenities and not the house itself. The indices estimated in this paper respect these quality changes and infer that the identified changes in $\mathrm{HI}$ indices are due to changes in quality at a local, neighbourhood level. The results also cast some doubt about the extent to which control by quality in house price index construction is an appropriate method when the main cause of house price change is external to the property.

\section{Conclusions}

This paper produces several house price indices for Spain and selected Spanish provinces controlled by quality using asking prices over a long-run period from 1995 to 2012. The paper utilises two hedonic models to fit the pricing process: the conventional Hedonic using time-dummies variables (HD) indices that does not allow the parameters to change with time and the imputed price Hedonic (HI), allowing parameters to change with time. The $\mathrm{HI}$ indices are built using a Laspeyres index definition.

The findings highlight that changes in quality is relevant in explaining house price increase in Spain and differences at a spatial level. In this respect, the paper makes an important contribution to understanding housing market dynamics and behaviour through providing a more informed insight to the Spanish market in what was a period of significant growth and later decline. The paper also and perhaps even more significantly adds to the knowledge base on how constant quality indices can differ appreciably from non-adjusted housing price indices, in this context the empirical study articulated in this paper supports theoretical principles.

The findings of this paper add to literature base regarding how different index methods within seemingly large datasets can incorporate bias in hedonic price indices due to the relevance of neighbourhood information in explaining price changes. The paper also highlights the different results depending on the hedonic methodology to estimate the index. The difference between the HD and the HI suggests that both methods together could capture the effect on prices coming from market innovations and is relevant in identifying the potential existence of price bubbles. The paper also discusses and tests the concept of a 'typical house' when calculating price indices. The results suggest that where a typical house is defined, in building either a Laspeyres or Fisher index with HD, it is only necessary to include housing attributes and let time dummies capture socio-economic changes.

The analysis, while having specific implications for housing in Spain, has wider transferable application for housing markets in other countries where seemingly high and unsustainable rates of price growth led to unsustainable levels of bank exposure due to lending in the property sector; a key ingredient of the financial crisis and problems in certain Euro-zone countries. In this respect, the fundamental message from the paper is that house price indices not controlling for quality and space-time effects can produce a distorting effect on the scale of both market growth and decline and thereby accentuate the impact of property and house prices at a macro-economic level.

\section{References}

Adair, A. S., Berry, J. N., \& McGreal, W. S. (1996). Hedonic modelling, housing submarkets and residential valuation. Journal of Property Research, 13(1), 67-83.

https://doi.org/10.1080/095999196368899

Anselin, L. (1999). Interactive techniques and exploratory spatial data analysis. In P. Longley, M. Goodchild, D. Maguire, \& D. Rhind (Eds.), Geographical information systems: principles, techniques, management and applications (pp. 251-264). New York: Wiley.

Bianconi, M., \& Yoshino, J. A. (2013). House price indexes and cyclical behaviour. International Journal of Housing Markets and Analysis, 6(1), 26-44.

https://doi.org/10.1108/17538271311305995 
Bank for International Settlements. (2008) Transmission mechanism for monetary policy in emerging market economies (BIS Papers No. 35). Retrieved from https://www.bis.org/publ/bppdf/bispap35.pdf\#page $=9$

Bollerslev, T., Patton, A. J., \& Wang, W. (2016). Daily house price indices: construction, modeling, and longer-run predictions. Journal of Applied Econometrics, 31, 1005-1025. https://doi.org/10.1002/jae.2471

Bowen, W. M., Mikelbank, A., \& Prestegaard, D. M. (2001). Theoretical and empirical considerations regarding space in hedonic housing price model applications. Growth and Change, 32(4), 466-490. https://doi.org/10.1111/0017-4815.00171

Case, B., \& Shiller, R. (1987). Prices of single family homes since 1970: new indexes for four cities (Paper No. 851). Cowles Foundation for Research in Economics, Yale University. https://doi.org/10.3386/w2393

Case, B., \& Wachter, S. (2005). Residential real estate price indices as financial soundness indicators: methodological issues (BIS Paper No. 21, pp. 197-211). IMF.

Clapman, E., Englund, P., Quigley, J., \& Redfearn, C. (2006). Revisiting the past and settling the score: index revision for house price derivatives. Real Estate Economics, 34(2), 275302. https://doi.org/10.1111/j.1540-6229.2006.00167.x

Clapp, J. (2004). A semi parametric method for estimating local house price indices. Real Estate Economics, 32(1), 127-160. https://doi.org/10.1111/j.1080-8620.2004.00086.x

Coulson, N. E. (2012). House price index methodologies. In International Encyclopedia of Housing and Home. Elsevier. https://doi.org/10.1016/B978-0-08-047163-1.00634-2

Diewert, W. E. (2010). Alternative approaches to measuring house price inflation (Discussion Paper No. 10-10). Department of Economics, The University of British Columbia, Vancouver, Canada.

Diewert, W. E., Heravi, S., \& Silver, M. (2009). Hedonic imputation versus time dummy hedonic indexes. In W. E. Diewert, J. S. Greenlees, \& C. R. Hulten (Eds.), Price index concepts and measurement. New York: NBER book.

Dorsey, R. E., Hu, H., Myre, W. J., \& Wang, H. C. (2010). Hedonic versus repeat-sales housing price indexes for measuring the recent boom-bust cycle. Journal of Housing Economics, 19, 87-105. https://doi.org/10.1016/j.jhe.2010.04.001

Dubin, R., Pace, K., \& Thibodeay, T. (1998). Spatial autoregression techniques for real estate data. Journal of Real Estate Literature, 7(1), 79-95. https://doi.org/10.1023/A:1008690521599

Ekeland, I., Heckman, J. L., \& Nesheim, L. (2002). Identifying hedonic models. American Economic Review, 92(2), 304-309. https://doi.org/10.1257/000282802320189447

Ekeland, I., Heckman, J. L., \& Nesheim, L. (2004). Identification and estimation of hedonic models. Journal of Political Economy, 112(S1), S60-S109. https://doi.org/10.1086/379947

Ericson, L. E., Song, H. S., Winstrand, J., \& Wilhelmsson, M. (2013). Regional house price index construction - the case of Sweden. International Journal of Strategic Property Management, 17(3), 278-304. https://doi.org/10.3846/1648715X.2013.822032

European Economy. (2012). Scoreboard for the surveillance of macroeconomic imbalances (Occasional Paper No. 92). Retrieved from https://ec.europa.eu/economy_finance/publications/occsaional, pp. paper/2012/pdf/ocp92_en_pdf

Eurostat. (2011). Consumer price index manual: theory and practice (Chapter 1, p. 3 and Chapter 9, pp. 18-19, versión corrected at 15 August 2010). Retrieved from https:/www.ilo.org/ public/English/bureau/stat/guides/cpi/\#manual

Eurostat. (2013). Handbook on residential property price indices (RPPIs). Retrieved from https://ec.europa.eu/eurostat/web/ products-manuals-and-guidelines/-/KS-RA-12-022
Gatzla, D. H., \& Haurin, D. R. (1998). Sample selection and biases in local house value indices. Journal of Urban Economics, 43(2), 199-222. https://doi.org/10.1006/juec.1997.2045

Geltner, D. (1993). Temporal aggregation in real estate return indices. Journal of the American Real Estate and Urban Economics Association, 21(2), 141-166.

https://doi.org/10.1111/1540-6229.00605

Getis, A., \& Ord, J. K. (1992). The analysis of spatial association by use of distance statistics. Geographical Analysis, 24(3), 189206. https://doi.org/10.1111/j.1538-4632.1992.tb00261.x

Goh, Y. M., Costello, G., \& Schwann, G. (2012). Accuracy and robustness of house price index methods. Housing Studies, 27(5), 643-666. https://doi.org/10.1080/02673037.2012.697551

Goodman, A. C., \& Thibodeau, T. G. (1995). Age-related heteroskedasticity in hedonic house price equations. Journal of Housing Research, 6(1), 25-42.

Griliches, Z. (1991). Hedonic price indexes and the measurement of capital and productivity: some historical reflections. In E. Berndt \& J. Triplett (Eds.), Fifty years of economic measurement: the jubilee of the conference on research in income and wealth (Vol. 54, pp. 185-202). Chicago: University of Chicago Press.

Grover, R., \& Grover, C. (2014). The role of house price indices in managing the integration of finance and housing markets in the European Union. Journal of European Real Estate Research, 7(3), 270-294. https://doi.org/10.1108/JERER-02-2014-0013

Haurin, D. R., Hendershott, P. H., \& Kim, D. (1991). Local house price indexes: 1982-1991. AREUEA Journal, 19(3), 451-472. https://doi.org/10.1111/1540-6229.00562

Helbich, M., Brunauer, W., Vaz, E., \& Nijkamp, P. (2013). Spatial heterogeneity in hedonic house price models: the case of Austria. Urban Studies, 51(2), 390-411. https://doi.org/10.1177/0042098013492234

Herath, S. K., \& Maier, G. (2010). The hedonic price method in real estate and housing market research: a review of the literature (pp. 1-21). Vienna, Austria: University of Economics and Business. Retrieved from https://ro.uow.edu.au/ cgi/viewcontent.cgi?referer=https://scholar.google.com/ scholar?hl=ca\&as_sdt=0\%2C5\&q=herath + and + maier +2010 \&btnG $=$ \&httpsredir $=1$ \&article $=1977 \&$ context=buspapers

Hill, R. (2011). Hedonic price indexes for housing (OECD Statistics Working Papers No. 2011/01). OECD Publishing.

Hill, R., \& Melser, D. (2008). Hedonic imputation and the price index problem: an application to housing. Economic Inquiry, 46(4), 593-608. https://doi.org/10.1111/j.1465-7295.2007.00110.x

Hill, R. J., \& Scholz, M. (2017). Can goespatial data improve house price indexes? A hedonic imputation approach with splines. Review of Income and Wealth (in press). https://doi.org/10.1111/roiw.12303

Hwang, M., \& Quigley, J. M. (2010). Housing price dynamics in time and space: predictability, liquidity and investor returns (Working Paper No. W08-007). IBER Program on Housing and Urban Policy.

Kiel, K. A., \& Zabel, J. E. (2008). Location, location, location: the $3 \mathrm{~L}$ approach to house price determination. Journal of Housing Economics, 17, 175-190. https://doi.org/10.1016/j.jhe.2007.12.002

Linneman, P. (1980). Some empirical results on the nature of the hedonic price function for the urban housing market. Journal of Urban Economics, 8(1), 47-68. https://doi.org/10.1016/0094-1190(80)90055-8

Mack, A., \& Martínez-García, E. (2011). A cross-country quarterly database of real house prices: a methodological note (Globalization and Monetary Policy Institute Working Pa- 
per No. 99). Federal Reserve Bank of Dallas. Retrieved from https://dallasfed.org/institute/wpapers/2011/0099.pdf

Maguire, P., Miller, R., Moser, P., \& Maguire, R. (2016). A robust house price index using sparse and frugal data. Journal of Property Research, 33(4), 293-308. https://doi.org/10.1080/09599916.2016.1258718

McGreal, W. S., \& Taltavull de La Paz, P. (2012). An analysis of factors influencing accuracy in the valuation of residential properties in Spain. Journal of Property Research, 29(1), 1-24. https://doi.org/10.1080/09599916.2011.589531

McGreal, W. S., \& Taltavull de La Paz, P. (2013). Implicit house prices: variation over time and space in Spain. Urban Studies, 50(10), 2024-2043. https://doi.org/10.1177/0042098012471978

McMillen, D. (2008). Changes in the distribution of house prices over time: structural characteristics, neighborhood or coefficients? Journal of Urban Economics, 64, 573-589. https://doi.org/10.1016/j.jue.2008.06.002

Mishkin, F. S. (2007). Housing and the monetary transmission mechanism (Working Paper No. 40). Retrieved from https://www. federalreserve.gov/pubs/feds/2007/200740/200740pap.pdf

Nagaraja, C. H., Brown, L. D., \& Wachter, S. S. (2014). Repeat sales house price index methodology. Journal of Real Estate Literature, 22(1), 23-46.

Nappi-Choulet, P. I., \& Maury, T. P. (2009). A spatiotemporal autoregressive price index for the Paris office property market. Real Estate Economics, 37(2), 305-340. https://doi.org/10.1111/j.1540-6229.2009.00244.x

Nikolov, K. (2014). Collateral amplification under complete markets (Working Paper No. 1716). European Central Bank.

Pace, R., Kelley, B., Gilley, R., Otis, W., \& Sirmans, C. F. (2000). A method for spatial-temporal forecasting with an application to real estate prices. International Journal of Forecasting, 16(2), 229-246. https://doi.org/10.1016/S0169-2070(99)00047-3

Peek, J., \& Wilcox, J. A. (1991). The measurement and determinants of single-family house prices. AREUEA Journal, 19(3), 353-382. https://doi.org/10.1111/1540-6229.00557

Prasad, N., \& Richards, A. (2008). Improving median housing price indexes through stratification. Journal of Real Estate Research, 30(1), 45-71.

Quigley, J. M. (1995). A simple hybrid model for estimating realestate price indexes. Journal of Housing Economics, 4, 1-12. https://doi.org/10.1006/jhec.1995.1001

Ramalho, A., \& Ramalho, J. (2011). Hedonic functions, hedonic methods, estimation methods and Dutot and Jevons house price indexes: are there any links? WP CEFAGE-UE Evora University. Retrieved from https://www.fep.up.pt
Rappaport, J. (2007). A guide to aggregate house price measures. In Economic review (pp. 41-71). Federal Reserve Bank of Kansas City.

Rosen, S. (1974). Hedonic price and implicit markets: product differentiation in pure competition. Journal of Political Economy, 82(1), 34-55. https://doi.org/10.1086/260169

Shiller, R. J. (1993). Measuring asset values for cash settlement in derivative markets: hedonic repeated measures indices and perpetual futures. The Journal of Finance, 48, 911-931. https://doi.org/10.1111/j.1540-6261.1993.tb04024.x

Shiller, R. J. (2008). Derivatives markets for home prices (Cowles Foundation Discussion Paper No. 1648). Yale University.

Silver, M., \& Heravi, S. (2007). The difference between hedonic imputation indexes and time dummy hedonic indexes. Journal of Business \& Economic Statistics, 25(2), 239-246. https://doi.org/10.1198/073500106000000486

Sirmans, S., MacDonald, L., Macpherson, D., \& Zietz, E. (2006). The value of housing characteristics: a meta analysis. The Journal of Real Estate Finance and Economics, 33, 215-240. https://doi.org/10.1007/s11146-006-9983-5

Stimson, J. A. (1985). Regression in space and time: a statistical essay. American Journal of Political Science, 29(4), 914-947. https://doi.org/10.2307/2111187

Syed, I. A., \& de Haan, J. (2017). Age, time, and price indexes: measuring the depreciation pattern of houses. Economic Inquiry, 55(1), 580-600. https://doi.org/10.1111/ecin.12383

Taltavull, P., \& White, M. (2016). The sources of house price change: identifying liquidity shocks to the housing market. Journal of European Real Estate Research, 9(1), 98-120. https://doi.org/10.1108/JERER-11-2015-0041

Taltavull de La Paz, P., López, E., \& Juárez, F. (2017). Ripple effect on housing prices. Evidence from tourist markets in Alicante, Spain. International Journal of Strategic Property Management, 21(1), 1-14. https://doi.org/10.3846/1648715X.2016.1241192

Tse, R. C. (2002). Estimating neghbourhood effects in house prices: towards a new hedonic model approach. Urban Studies, 39(7), 1165-1180. https://doi.org/10.1080/00420980220135545

Waltl, S. R. (2016). A hedonic house price index in continuous time. International Journal of Housing Markets and Analysis, 9(4), 648-670. https://doi.org/10.1108/IJHMA-10-2015-0066

Wood, R. (2005). A comparison of UK residential house price indices. BIS Paper, 21, 212-227.

Wu, J., Deng, Y., \& Liu, H. (2014). House price index construction in the nascent housing market: the case of China. Journal of Real Estate Finance and Economics, 48, 522-545. https://doi.org/10.1007/s11146-013-9416-1 